\title{
Fabrication and Optical Properties of La-doped ZnO Thin Films
}

\author{
Jing-hua Xu,Shu Cui,Chengyou Liu
}

Department of Physics, Tonghua Normal University, Tonghua, Jilin 134002, China;

47837964@qq.com

Key words: La-doped, ZnO thin films, optical property, morphology

\begin{abstract}
La-doped $\mathrm{ZnO}$ thin films were deposited on the substrates of slide glass and Si by sol-gel method. The La/Zn ratio was 1\%, 2\%, 3\%. All the samples were characterized by X-ray diffraction (XRD), atomic force microscope (AFM), ultra-violet spectrometer (UVS) and photoluminescence (PL). All the samples have nice wurtzite structure. The morphology of the samples have flat surface. The peak of UV luminescence had a blue shift with the increase of La/Zn molar ratio.
\end{abstract}

\section{Introduction}

$\mathrm{ZnO}$ is a semiconductor material with wide band gap and wurtzite structure, its band gap is about $3.37 \mathrm{ev}$ and its exciton binding energy is up to $60 \mathrm{meV}$ at room temperature, is attracting more attention because of its good optical and electrical properties. Doping different metal atoms or ions into $\mathrm{ZnO}$ can change the structure and band gap of $\mathrm{ZnO}$, endowing doped $\mathrm{ZnO}$ with new characteristics that is different from the $\mathrm{ZnO}$ dilute. Rare earth-doped $\mathrm{ZnO}$ is a research focus in recent years, but doping rare earth with the sol-gel method is rare. This experiment, adapting the gel-sol method, grows La-doped nanoZnO thin films in the Si film (P type 100 direction) and ordinary glass plate, which aims to study the effects from La with different concentrations on the $\mathrm{ZnO}$ thin films, such as, the structure, UV transmittance and surface morphology, luminescence resulting at room temperature ${ }^{[1-5]}$.

\section{The Experiment}

$\left(\mathrm{CH}_{3} \mathrm{COO}\right)_{2} \mathrm{Zn} \cdot 2 \mathrm{H}_{2} \mathrm{O}$ and $\mathrm{La}\left(\mathrm{NO}_{3}\right)_{3} \cdot 6 \mathrm{H}_{2} \mathrm{O}$ were weighed by electronic balance according to the Molar Ratio and dissolved in ethylene glycol, then added with metal ion equimolar monoethanolamine. Putting them in the reaction kettle and stirring for 1 hour at $60^{\circ} \mathrm{C}$, which finally forms the colorless transparent homogeneous solution. Then painting films evenly after 72-hour aging and placing the samples in the box-type resistance furnace for annealing. the films on simple glass substrates were annealed in air at $550^{\circ} \mathrm{C}$ for 1 hour, and the films on Si substrates were annealed at $900^{\circ} \mathrm{C}$ for 1 hour, respectively. The annealing temperature for ordinary glass substrate and $\mathrm{Si}$ substrate is $550^{\circ} \mathrm{C}$ and $900^{\circ} \mathrm{C}$ respectively, and the annealing time is 1 hour. Later, cooling them in the furnace to room temperature. At last, La-doped $\mathrm{ZnO}$ thin films with the doping concentration of $1 \%, 2 \%, 3 \%$ were obtained.

\section{Results and Discussion}

\subsection{The crystal structure of La -doped ZnO thin films}

The XRD patterns of La -doped $\mathrm{ZnO}$ thin films has been depicted in Figure 1. All of the samples showed that La-doped $\mathrm{ZnO}$ thin films were still had the polycrystalline hexagonal wurtzite structure and had no obvious preferential orientation. These thin films, as a result of different preparation methods and experimental conditions, differ from those $\mathrm{La}$ and $\mathrm{Nd}$ doped $\mathrm{ZnO}$ thin films made by Wen Jun. Fig.1 also shows that with the increase of doping concentration, the diffraction peaks obviously move toward the large angular direction, which indicates that the $\mathrm{C}$ axis of La-doped $\mathrm{ZnO}$ thin films shortens ${ }^{[6,7]}$. 


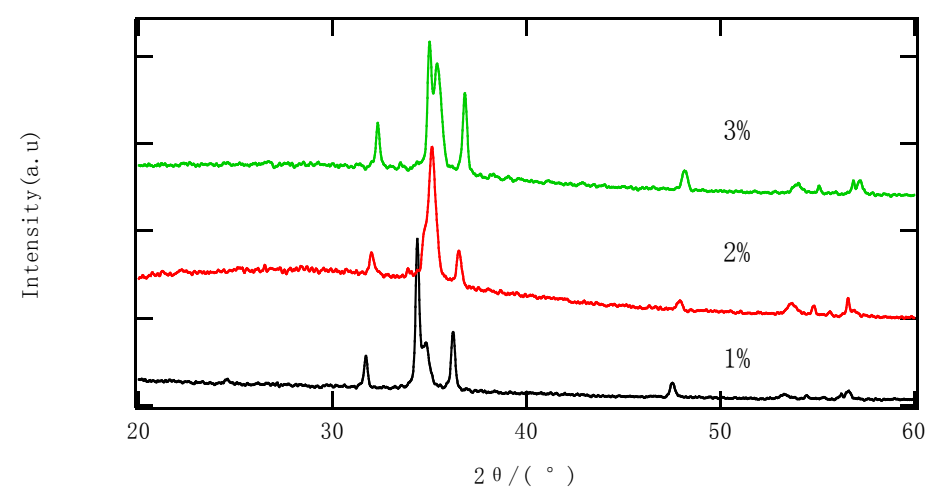

Fig.1 XRD pattens of La -doped $\mathrm{ZnO}$ thin films annealed at $900 \quad{ }^{\circ} \mathrm{C}$.

\subsection{The transmission spectra of La -doped ZnO thin films}

Fig. 2 is the transmission spectrum of the different doping concentration samples with glass slide as the substrate annealed at $500^{\circ} \mathrm{C}$. All of the data were collected at room temperature. Fig.2 (a) shows that transmissivity decline sharply around the 380nm UV, besides, there are obvious ultraviolet absorption edge, and the transmission side appears obvious blue shift with the increase of doping concentration, which indicates that the doping of rare earth La can enlarge the gap width of $\mathrm{ZnO}^{[8-10]}$. Fig.2 (b) refers to the specific band gap width of La-doped $\mathrm{ZnO}$ thin films. The band gap width of the $1 \%$ sample is $3.32 \mathrm{eV}$, the $2 \%$ sample $3.40 \mathrm{eV}$, and the $3 \%$ sample $3.36 \mathrm{eV}$. It is clear that La-doped $\mathrm{ZnO}$ thin films can better regulate the the band gap width of $\mathrm{ZnO}$ thin films.
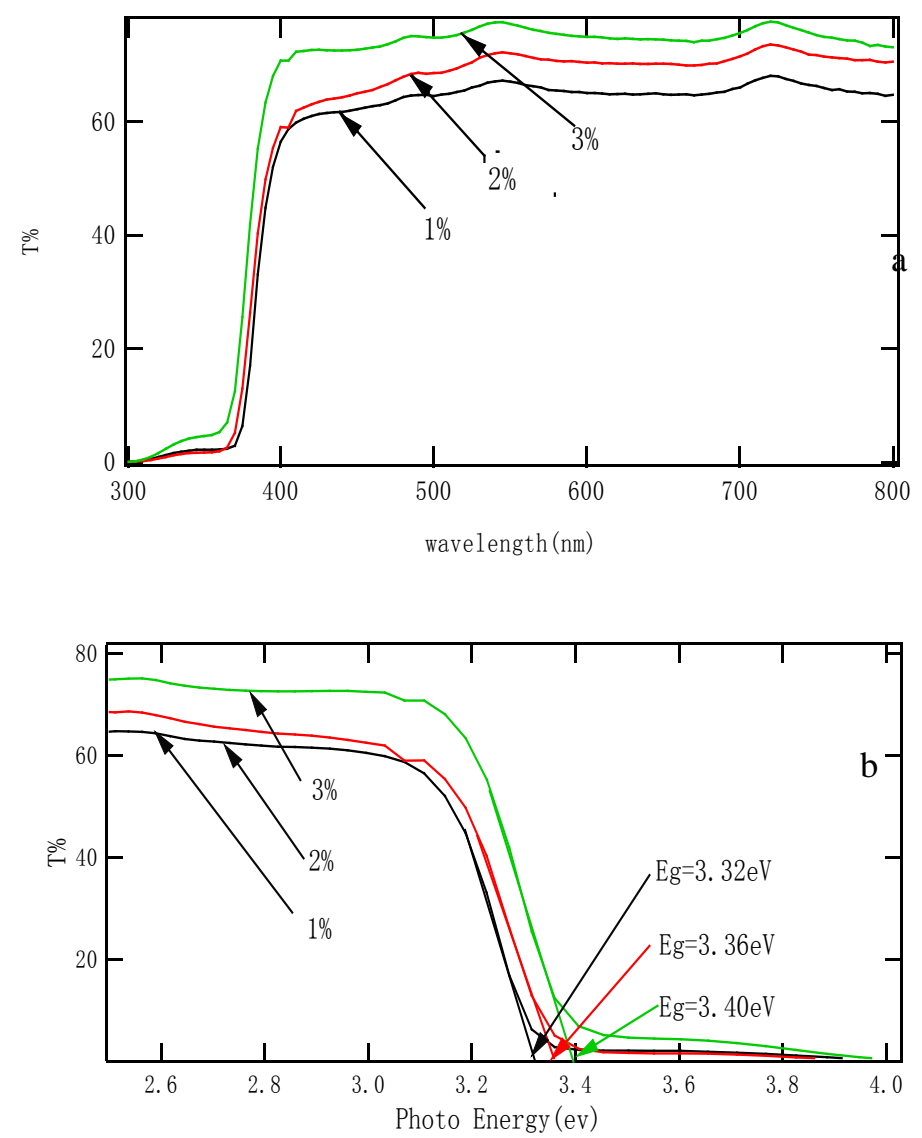

Fig.2 Transmission spectra of La-doped $\mathrm{ZnO}$ thin films annealed at $500^{\circ} \mathrm{C}$.

(a) Wavelength and transmittance diagram

(b) Photo Energy and transmittance rate diagram 


\subsection{Surface Morphology of La-doped ZnO thin films}

The AFM images of La-doped $\mathrm{ZnO}$ thin films annealed at $900^{\circ} \mathrm{C}$ for 1 hour were showed in Fig.3. La-doped $\mathrm{ZnO}$ thin film samples of different concentrations appear to be granular, and the growth of particles is relatively uniform, which has a great relationship with the selection of $\mathrm{Si}$ substrate and higher annealing temperature.
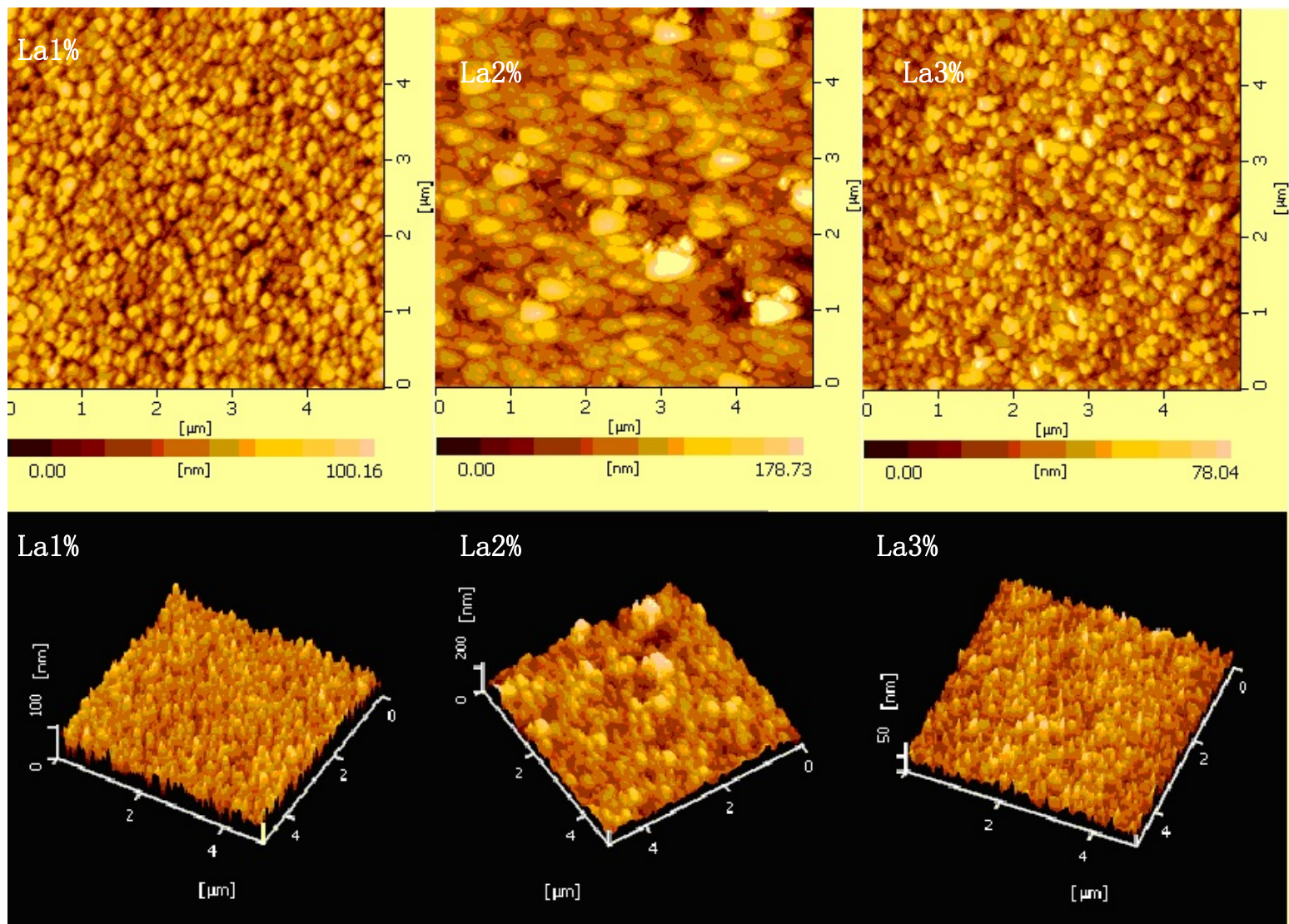

Fig.3 AFM images of $\mathrm{ZnO}$ samples annealed at $900^{\circ} \mathrm{C}$

\subsection{Photoluminescence Properties of Samples}

Fig.4 illustrates the room-temperature PL spectra of the $\mathrm{ZnO}$ samples annealed at $900^{\circ} \mathrm{C}$.La-doped $\mathrm{ZnO}$ thin films have better luminescent properties, besides, the ultraviolet luminescence peaks shift toward short wavelength with the increase of doping concentration, which is consistent with the phenomenon observed through the transmission spectrum.

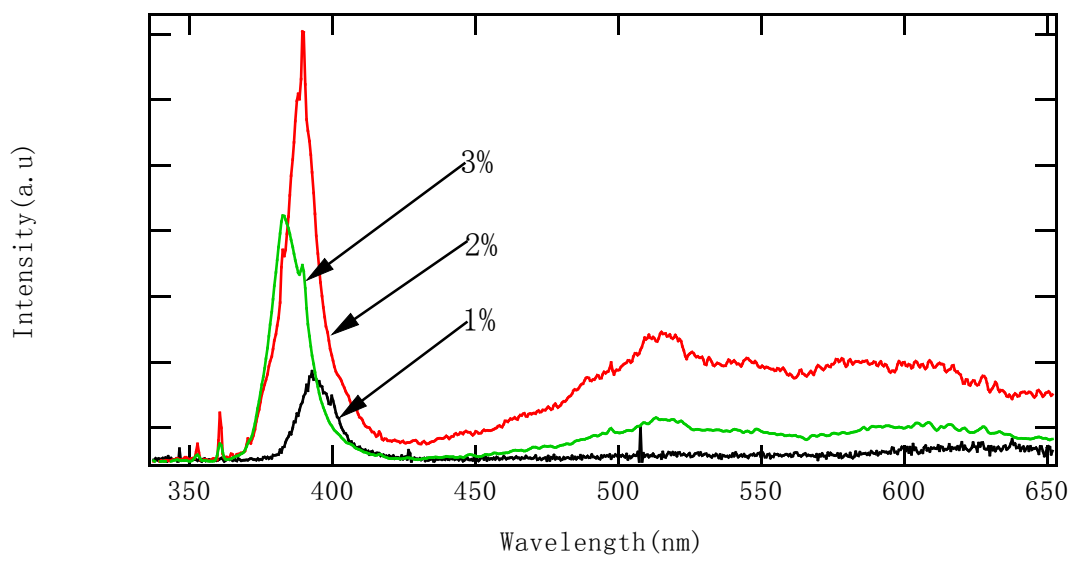

Fig.4 PL spectra of samples obtained at $900^{\circ} \mathrm{C}$; 


\section{Conclusions}

La-doped $\mathrm{ZnO}$ thin films of different concentrations are prepared by sol-gel method. Analysis through XRD, UVS, AFM and PL spectrum shows that the La-doped ZnO thin films of different concentrations have hexagonal wurtzite structures. What's more, the surface was smooth, the particle is uniform and the ultraviolet luminescence peaks are enhanced significantly and shift toward short wavelength with the increase of doping concentration.

\section{References}

[1]J.T. Chena, J. Wanga, F. Zhanga,et al.The effect of La doping concentration on the properties of zinc oxide films prepared by the sol-gel method[J]. Journal of Crystal Growth , 2008 (310): 2627-2632.

[2]I.Stambolova,K.Konstantinov,S.Vassilev,P.Peshev,et al.Lanthanum doped $\mathrm{SnO} 2$ and $\mathrm{ZnO}$ thin films sensitive to ethanol and humidity [J].Materials Chemistry and Physics 63(2000)104-108

[3]T. M. Williams, D. Hunter,A. K. Pradhan.Photoinduced piezo-optical effect in Er doped ZnO films[J].Applied physics letters, 2006 (89) : 043116-1-043116-3.

[4]Keh-moh Lin, Paijay Tsai.Growth mechanism and characterization of $\mathrm{ZnO}$ : Al multi-layered thin films by sol-gel technique[J]. Thin Solid Films 2007 (515) :8601-8604.

[5] D.G. Thomas, J. Phys. Chem. Solids 15 (1960) 86.

[6]Wenjun. Fabrication and Optical Properties of la and Nd-doped ZnO Thin Films

[7]YANG Jing-hai,GAO Ming, ZHANG Yong-jun, et al. CHEM. RES. CHINESE UNIVERSITIES,2008,3,266.

[8] Pereira A. S. , Peres M. , Soares M. J. , Alves E. , Neves A. , Monteiro T. , Trindade T. . Nanotechnology, 2006, 17, 834

[9] Bofiani Z., Derkowska B., Dalasinski P., et al., Optics Communications, 2006, 267, 433

[10] Pereira A. S. , Peres M. , Soares M. J. , Alves E. , Neves A. , Monteiro T. , Trindade T. . Nanotechnology, 2006, 17, 834 